\title{
New Predictive Equations for Serum lonized Calcium in Hospitalized Patients
}

\author{
Javier Mateu-de Antonio \\ Department of Pharmacy, Hospital del Mar, Barcelona, Spain
}

\author{
Key Words \\ Calcium · Calcium metabolism disorders · Hospitalization . \\ Hypocalcemia . Predictive value of tests
}

\begin{abstract}
Objective: To study a new and easy way to calculate equations to predict ionized calcium $\left(\mathrm{Ca}^{2+}\right)$ for adult hospitalized patients with the usual laboratory and clinical parameters. Subjects and Methods: This retrospective observational study was conducted in a third-level university hospital. An initial learning cohort (cohort L: 269 patients) was selected to derive the new equations. These equations were tested in a validation of another cohort (cohort V: 146 patients). Patients selected were hospitalized adults who had simultaneous determinations of $\mathrm{Ca}^{2+}$ and serum total calcium (CaTot). They were classified using their estimated glomerular filtration rate (GFRe) into normal function, moderate and severe kidney dysfunction. Demographic and biochemical parameters, in addition to comorbidities, were collected from hospital databases. Nine published equations to predict $\mathrm{Ca}^{2+}$ and 2 widely used equations to predict corrected CaTot were also selected to be compared to newer equations for accuracy in detecting serum calcium alterations. New equations were derived by a multiple linear-regression analysis from patients in cohort L. Results: Three equations were derived containing the CaTot square root as the main independent variable. Equation 1: $\mathrm{Ca}^{2+}=0.815 \times \mathrm{CaTot}^{0.5}$. Equation $2: \mathrm{Ca}^{2+}=0.826 \times \mathrm{CaTot}^{0.5}-0.023 \times$ renal function.
\end{abstract}

Equation 3: $\mathrm{Ca}^{2+}=0.813 \times \mathrm{CaTot}^{0.5}-0.006 \times$ albumin $^{0.75}+$ 0.079 . These equations performed better than published equations to predict $\mathrm{Ca}^{2+}$ when their error measures were analyzed in cohort $\mathrm{V}$, even in special populations such as critically ill and very old patients. Conclusions: Three new equations predicting $\mathrm{Ca}^{2+}$ were derived requiring easily available clinical and laboratory parameters. They could be valuable in predicting hypocalcemia but are of limited use in hypercalcemia.

(c) 2015 S. Karger AG, Basel

\section{Introduction}

Calcium plays an essential role in many enzymes, membrane transporters and multiple physiological processes [1]. It is the most abundant mineral in the human body and mainly stored in the bones [2]. In serum, calcium exists in three forms: bound to proteins, predominantly albumin (40-50\%), forming complexes with anions such as citrate, lactate or phosphate (5-10\%), and in a free ionized form known as ionized calcium $\left(\mathrm{Ca}^{2+} ; 45-50 \%\right)$ [2]. The $\mathrm{Ca}^{2+}$ is the biologically active form [3], and its measurement has been suggested as a reference test for calcium status [4-7]. However, serum total calcium (CaTot) determination is still the most used test in health centers $[1,2]$ that needs subsequent correction by equations to obtain a 'corrected calcium' $[1,2]$. These equations are based on the fact that CaTot is lower in hypoalbuminemia

\begin{tabular}{ll}
\hline KARGER & $\begin{array}{l}\text { ( ) 2015 S. Karger AG, Basel } \\
1011-7571 / 15 / 0253-0219 \$ 39.50 / 0 \quad \text { Karger }\end{array}$ \\
$\begin{array}{l}\text { E-Mail karger@karger.com } \\
\text { www.karger.com/mpp }\end{array}$ & $\begin{array}{l}\text { This is an Open Access article licensed under the terms of the } \\
\text { Creative Commons Attribution-NonCommercial 3.0 Un- } \\
\text { ported license (CC BY-NC) (www.karger.com/OA-license), } \\
\text { applicable to the online version of the article only. Distribu- } \\
\text { tion permitted for non-commercial purposes only. }\end{array}$
\end{tabular}

Javier Mateu-de Antonio, PhD

Department of Pharmacy

Hospital del Mar, Passeig Marítim, 25-29

ES-08003 Barcelona (Spain)

E-Mail FMateu@ hospitaldelmar.cat 
than in normoalbuminemia, but being the calcium bound to albumin the only fraction decreased and not the $\mathrm{Ca}^{2+}$. 'Corrected calcium' equations try to deduce CaTot supposing normoalbuminemia. The $\mathrm{Ca}^{2+}$ test is viewed by many clinicians as neither practical due to technical reasons nor cost-effective for all patients $[1,2]$, or, conversely, it is ordered excessively leading to increased costs [8]. Equations to predict $\mathrm{Ca}^{2+}$ could be an alternative when this value is not available, difficult to obtain or for deciding about further tests. However, predictive equations for $\mathrm{Ca}^{2+}$ have been considered complex, outdated and unadapted to patients, since many of them have been derived from laboratory tests or from a healthy population $[1,2]$.

The objective of this study was to derive new equations to predict $\mathrm{Ca}^{2+}$ for adult hospitalized patients. These equations were intended to contain the usual laboratory or clinical parameters and to be easily calculable.

\section{Subjects and Methods}

\section{Study Design and Setting}

This was a retrospective observational study conducted in a third-level university hospital of 400 beds. The Clinical Research Ethics Committee of the institution approved the study.

\section{Patients}

An initial learning cohort (cohort $\mathrm{L}$ ) was recruited to derive the equations (January 2007 to June 2008). It comprised 269 patients amongst 1,008 patients screened. Later, a validation cohort (cohort $\mathrm{V}$ ) was recruited to test the new equations (December 2009 to December 2010). It comprised 146 patients amongst 877 patients screened.

During the two study periods, the computerized hospital records were screened for all patients admitted if they were adults ( $\geq 18$ years old) and they had had a simultaneous blood determination of $\mathrm{Ca}^{2+}$ and CaTot. These initially selected patients were further screened for serum values of creatinine, sodium, potassium, phosphate, magnesium, total proteins (ProtTot), albumin (Alb) and glycemia obtained in a simultaneous blood drawing to the $\mathrm{Ca}^{2+}$ sample. Patients without these values were then excluded.

\section{Laboratory Tests}

Once obtained, venous blood samples were centrifuged and the supernatant serum separated. These serum samples were refrigerated to $0-4^{\circ} \mathrm{C}$ when determined immediately or they were frozen until delayed determination. $\mathrm{Ca}^{2+}$ was measured by ion selective electrode direct potentiometry and was adjusted for $\mathrm{pH} 7.4$ by an analyzer-based equation (GEM Premier 3000, Instrumentation Laboratory-Werfen, Bedford, Mass., USA). CaTot was determined by automated spectrophotometry. The remaining parameters were determined by the usual automated laboratory techniques. All samples were analyzed by the same laboratory. The laboratory operates $24 \mathrm{~h}$ per day, 7 days per week. The majority of samples were processed within $2 \mathrm{~h}$. When convenient, conventional units were converted to SI units.

\section{Data Collected}

Each patient contributed only with the first determination of $\mathrm{Ca}^{2+}$ during his/her admission. Normocalcemia was defined as a $\mathrm{Ca}^{2+}$ between 1.16 and $1.34 \mathrm{mmol} / \mathrm{l}$. Lower values were considered as hypocalcemia and higher values as hypercalcemia. The CaTot normal range was $2.12-2.62 \mathrm{mmol} / \mathrm{l}$. Additional data collected were department of admission, diagnosis and demographics. Patients were classified depending on their renal function (RF), estimated by the CKD-EPI (Chronic Kidney Disease Epidemiology Collaboration) equation [9] into normal function (estimated glomerular filtration rate, GFRe $\geq 60 \mathrm{ml} / \mathrm{min} / 1.73 \mathrm{~m}^{2}$ ), moderate dysfunction $\left(<60-30 \mathrm{ml} / \mathrm{min} / 1.73 \mathrm{~m}^{2}\right)$ and severe dysfunction $(<30$ $\left.\mathrm{ml} / \mathrm{min} / 1.73 \mathrm{~m}^{2}\right)$. Patients were also classified as hypoglycemic (glycemia $<4.44 \mathrm{mmol} / \mathrm{l})$, normoglycemic $(4.44-6.11 \mathrm{mmol} / \mathrm{l}$ ) and hyperglycemic ( $>6.11 \mathrm{mmol} / \mathrm{l})$. Comorbidities affecting calcium metabolism were also recorded: acute and/or chronic kidney disease, heart failure, hypertension, diabetes, liver failure, chronic obstructive pulmonary disease, alcoholism, dyslipidemia, active neoplasm, hypo- or hyperthyroidism, hypo- or hyperparathyroidism, and bone diseases.

\section{Published Calcium Predictive Equations}

The medical literature was searched for predictive equations of $\mathrm{Ca}^{2+}$. Search results were limited to equations applied to adults, with variables easily obtainable, and not designed for specific diseases. Additional references were obtained screening the publications initially found. Widely used equations to calculate corrected CaTot were also selected to compare the accuracy in detecting calcium alterations. Ten equations were found that were used as comparators [10-19]. They are shown in table 1. For each patient in cohort V, predicted $\mathrm{Ca}^{2+}$ and corrected CaTot were calculated using all equations.

\section{Statistical Analysis}

Patients with outlier values for $\mathrm{Ca}^{2+}$ were excluded. Quantitative variables were tested for normal distribution. Those without this condition were transformed by the box Cox transformation. Linear transformations were also applied to change a variable scale when considered appropriate. Serum variables, transformed when necessary, demographics, and comorbidities, as dichotomous variables, were tested initially as independent variables for univariate linear regression taking $\mathrm{Ca}^{2+}$ as the dependent variable. Independent variables resulting with a $\mathrm{p}$ value $\leq 0.15$ were selected to perform a further multiple linear-regression analysis with a stepwise approach. Different sets of variables were manually selected to obtain the simplest equations. Reliability was measured by the intraclass concordance coefficient for a single measure. Values of +1 denote perfect concordance, values of -1 perfect reverse concordance, and a value of zero absence. Accuracy was measured with mean error, mean absolute error, mean absolute percentage error and root mean square error. Agreement between equations in classifying calcemia as hypo-, hyper- or normocalcemia was measured by the weighted kappa coefficient for categorical variables. A kappa of 1 indicates perfect agreement, whereas a kappa of 0 indicates agreement by chance. Sensibility, specificity and likelihood ratios were calculated for detecting hypocalcemia. For a positive likelihood ratio, higher values indicate a larger increase in the change in probability of the disease. For a negative likelihood ratio, smaller values indicate a larger decrease in the change in probability of the disease. Comparisons of quantitative variables were performed 
Table 1. Published predictive equations for serum calcium

\begin{tabular}{|c|c|c|c|c|}
\hline Equation & Year & Mathematical expression & Study characteristics & Ref. \\
\hline McLean-Hastings & 1935 & $\begin{array}{l}\mathrm{Ca}^{2+}=\text { CaTot }-0.122 \times \text { ProtTot }-0.006+0.5 \times[(0.024 \times \\
\left.\text { CaTot })+(0.122 \times \text { ProtTot }- \text { CaTot }+0.006)^{2}\right]^{0.5}\end{array}$ & $\begin{array}{l}\text { In vitro model of frog heart; derived from an } \\
\text { undetermined number of serum samples }\end{array}$ & 10 \\
\hline Zeisler & 1954 & $\begin{array}{l}\mathrm{Ca}^{2+}=[(250.50 \times \mathrm{CaTot})-(\operatorname{ProtTot} \times 0.375)] /[4.01 \times \\
\text { ProtTot }+260.52]\end{array}$ & $\begin{array}{l}\text { Theoretical formula derived from McLean-Hastings } \\
\text { nomogram; neither learning nor validation samples }\end{array}$ & 11 \\
\hline Pottgen & 1976 & $\begin{array}{l}\mathrm{Ca}^{2+}=(721.5 \times \text { CaTot }-\mathrm{K}) /(120.24 \times \mathrm{K}+721.5) \\
\mathrm{K}=(0.19 \times \text { ProtTot })+\text { albumin }\end{array}$ & $\begin{array}{l}\text { Corrected from Zeisler equation; derived from } 44 \\
\text { inpatients; no validation cohort }\end{array}$ & 13 \\
\hline Siggaard-Andersen & 1983 & $\begin{array}{l}\mathrm{Ca}^{2+}=0.8333 \times \mathrm{Ca}^{2+} \text { calculated by the McLean-Hastings } \\
\text { equation }\end{array}$ & $\begin{array}{l}\text { Theoretical correction of McLean-Hastings equation; } \\
24 \text { undetermined samples to calculate accuracy }\end{array}$ & 14 \\
\hline Forster & 1985 & $\begin{array}{l}\text { For critically ill surgical patients: } \\
\mathrm{Ca}^{2+}=0.225+(0.55 \times \text { CaTot })-(0.007 \times \text { albumin })\end{array}$ & $\begin{array}{l}\text { Derived from } 389 \text { inpatient samples; no validation } \\
\text { cohort }\end{array}$ & 15 \\
\hline Pfitzenmeyer & 2007 & $\begin{array}{l}\text { For patients of } \geq 80 \text { years old: } \\
\mathrm{Ca}^{2+}=0.592-0.00449 \text { ProtTot }+0.410 \times \text { CaTot }\end{array}$ & $\begin{array}{l}\text { Derived from } 294 \text { inpatient samples; validation cohort: } \\
77 \text { patient samples }\end{array}$ & 16 \\
\hline \multicolumn{5}{|c|}{ General predictive equations for CaTot } \\
\hline Payne & 1973 & CaAdj $=$ CaTot $-0.025 \times$ albumin +1 & Derived from 200 patient samples; no validation cohort & 17 \\
\hline James & 2008 & CaAdj $=$ CaTot $+[0.012 \times(39.9-$ albumin $)]$ & $\begin{array}{l}\text { Derived from } 4,613 \text { outpatient samples; validation } \\
\text { cohort: } 1,538 \text { outpatient samples }\end{array}$ & 18 \\
\hline
\end{tabular}

Equations were transformed to SI units when necessary. CaAdj $=$ Adjusted total calcium.

by the Mann-Whitney U test and comparisons of qualitative variables by the Fisher exact test. The agreement between each predictive equation and the $\mathrm{Ca}^{2+}$ measured were plotted in a Bland-Altman plot. The limits of agreement for each comparison were set at an average difference \pm 1.96 SD of the difference.

Data were analyzed using IBM SPSS Statistics 19.0 (IBM Corporation, Armonk, N.Y., USA) and Microsoft Excel 2010 (Microsoft Corporation, Redmond, Wash., USA).

\section{Results}

Cohort $\mathrm{L}$ and cohort $\mathrm{V}$ differed in several parameters as shown in table 2. Cohort $\mathrm{V}$ included more males, presented worse GFRe and had more comorbidities. In contrast, it presented a lower neoplasm rate and less mortality. Admission departments differed also between cohorts. In cohort $\mathrm{L}$, the range of $\mathrm{Ca}^{2+}$ was $0.78-1.56$ $\mathrm{mmol} / \mathrm{l} ; 120$ (44.6\%) patients were hypocalcemic and 26 (9.7\%) hypercalcemic. In cohort $\mathrm{V}$, the range of $\mathrm{Ca}^{2+}$ was $0.59-1.60 \mathrm{mmol} / \mathrm{l}$, and 87 (59.6\%) patients presented hypocalcemia and 7 (4.8\%) were hypercalcemic. Indepen- dent variables that initially entered the analysis were transformed age $[\log (100$ - age $)]$, sex, transformed CaTot (CaTot ${ }^{0.5}$ or CaTot square root), ProtTot, transformed albumin $\left(\mathrm{Alb}^{0.75}-2.2\right)$, transformed creatinine $\left(\right.$ Creat $\left.^{-0.87}\right)$, sodium, transformed potassium $\left(\mathrm{K}^{0.25}\right)$, magnesium, phosphate, RF (normal function $=0$; moderate dysfunction $=1$; severe dysfunction $=2$ ), glycemic status (hypoglycemia $=-1$; normoglycemia $=0$; hyperglycemia $=1$ ), and comorbidities shown in table 2.

The univariate analysis found only 9 variables to affect $\mathrm{Ca}^{2+}$ : transformed CaTot $(\mathrm{F}=37,829.57, \mathrm{p}<0.001)$, ProtTot $(\mathrm{F}=14.21, \mathrm{p}<0.001)$, transformed albumin $(\mathrm{F}=$ 10.27, $\mathrm{p}=0.002)$, transformed potassium $(\mathrm{F}=5.75, \mathrm{p}=$ $0.018), \mathrm{RF}(\mathrm{F}=3.74, \mathrm{p}=0.054)$, sodium $(\mathrm{F}=3.07, \mathrm{p}=$ $0.081)$, diabetes $(\mathrm{F}=2.99, \mathrm{p}=0.085)$, transformed creatinine $(\mathrm{F}=2.44, \mathrm{p}=0.119)$, and chronic obstructive pulmonary disease $(\mathrm{F}=2.38, \mathrm{p}=0.124)$. The remaining variables were discarded for further analysis. In the multivariate analysis, several sets of variables had to be discarded for problems in multicollinearity, autocorrelation and independence. Diabetes and chronic obstructive 
Table 2. Characteristics of cohorts $\mathrm{L}$ and $\mathrm{V}$

\begin{tabular}{|c|c|c|c|}
\hline & Cohort L & Cohort V & $\mathrm{p}$ value \\
\hline \multicolumn{4}{|l|}{ Demographics } \\
\hline Patients, $\mathrm{n}$ & 269 & 146 & \\
\hline Age, years & $71.0[55.5-78.0]$ & $70.0[56.8-78.0]$ & 0.889 \\
\hline Male/female sex & $146 / 123(54.3 / 45.7)$ & $99 / 47(67.8 / 32.2)$ & 0.009 \\
\hline $\mathrm{GFRe}^{\mathrm{a}}, \mathrm{ml} / \mathrm{min} / 1.73 \mathrm{~m}^{2}$ & $60.5[34.7-85.6]$ & $38.3[17.1-81.2]$ & $<0.001$ \\
\hline $\mathrm{Ca}^{2+}, \mathrm{mmol} / \mathrm{l}$ & $1.18[1.08-1.25]$ & $1.13[1.06-1.21]$ & 0.003 \\
\hline CaTot, $\mathrm{mmol} / \mathrm{l}$ & $2.07[1.87-2.27]$ & $2.07[1.92-2.20]$ & 0.917 \\
\hline Type of patient medical/surgical/trauma & $191 / 73 / 5(71.0 / 27.1 / 1.9)$ & $107 / 34 / 5(73.3 / 23.3 / 3.4)$ & 0.450 \\
\hline Critically ill patients ${ }^{\mathrm{b}}$ & $36(13.4)$ & $12(8.2)$ & 0.148 \\
\hline \multicolumn{4}{|l|}{ Comorbidities } \\
\hline Hypertension & $151(56.1)$ & $106(72.6)$ & 0.001 \\
\hline Neoplasm & $122(45.4)$ & $47(32.2)$ & 0.012 \\
\hline Acute renal impairment moderate/severe & $75 / 56(27.9 / 20.8)$ & $33 / 66(22.6 / 45.2)$ & $<0.001$ \\
\hline Diabetes mellitus & $63(23.4)$ & $64(43.8)$ & $<0.001$ \\
\hline Dyslipidemia & $61(22.7)$ & $53(36.3)$ & 0.04 \\
\hline Chronic renal impairment & $54(20.1)$ & $81(55.5)$ & $<0.001$ \\
\hline Chronic liver disease & $42(15.6)$ & $22(15.1)$ & 1.00 \\
\hline Chronic obstructive pulmonary disease & $40(14.9)$ & $30(20.5)$ & 0.170 \\
\hline Chronic heart failure & $33(12.3)$ & $26(17.8)$ & 0.141 \\
\hline Chronic alcoholism & $26(9.7)$ & $16(11.0)$ & 0.734 \\
\hline Bone diseases & $22(8.2)$ & $10(6.8)$ & 0.703 \\
\hline Hypothyroidism/hyperthyroidism & $19 / 2(7.1 / 0.7)$ & $7 / 10(4.8 / 6.8)$ & 0.001 \\
\hline Hypoparathyroidism/hyperparathyroidism & $1 / 25(0.4 / 9.3)$ & $32 / 7(21.9 / 4.8)$ & $<0.001$ \\
\hline \multicolumn{4}{|l|}{ Initial department of admission } \\
\hline General surgery & $53(19.7)$ & $17(11.6)$ & 0.040 \\
\hline Medical oncology & $34(12.6)$ & $2(1.4)$ & $<0.001$ \\
\hline Internal medicine & $24(8.9)$ & $3(2.1)$ & 0.006 \\
\hline Nephrology & $24(8.9)$ & $70(47.9)$ & $<0.001$ \\
\hline Gastroenterology & $18(6.7)$ & $10(6.8)$ & 1.000 \\
\hline Hematology & $15(5.6)$ & $2(1.4)$ & 0.040 \\
\hline Intensive care unit & $12(4.5)$ & $13(8.9)$ & 0.084 \\
\hline Other departments & $89(33.1)$ & $29(19.9)$ & - \\
\hline \multicolumn{4}{|l|}{ Outcomes } \\
\hline Length of stay, days & $18.0[10.0-34.0]$ & $16.0[8.0-31.5]$ & 0.204 \\
\hline Mortality & $60(22.3)$ & $14(9.6)$ & 0.001 \\
\hline
\end{tabular}

Values are expressed in medians with quartile 1 to quartile 3 in square brackets or alternatively in numbers with percentages in parentheses. ${ }^{a}$ Calculated by the CKD-EPI 2009 equation. ${ }^{b}$ At the time of $\mathrm{Ca}^{2+}$ determination.

pulmonary disease lost significance in all cases. Finally, 3 equations were selected to be tested in cohort $\mathrm{V}$ (units: $\mathrm{Ca}^{2+}$ in $\mathrm{mmol} / \mathrm{l}$, CaTot in $\mathrm{mmol} / \mathrm{l}$, Alb in $\left.\mathrm{g} / \mathrm{l}\right)$ :

Equation 1: $\mathrm{Ca}^{2+}=0.815 \times \mathrm{CaTot}^{0.5}$

corrected $\mathrm{R}^{2}=0.993, \mathrm{~F}=37,829.57$, standard error of the estimate $(\mathrm{SEE})=0.395, \mathrm{p}<0.001$

Equation 2: $\mathrm{Ca}^{2+}=0.826 \times \mathrm{CaTot}^{0.5}-0.023 \times \mathrm{RF}$

corrected $\mathrm{R}^{2}=0.993, \mathrm{~F}=19,527.65, \mathrm{SEE}=0.389, \mathrm{p}<0.001$

Equation 3: $\mathrm{Ca}^{2+}=0.813 \times \mathrm{CaTot}^{0.5}-0.006 \times \mathrm{Alb}^{0.75}+0.079$

corrected $\mathrm{R}^{2}=0.993, \mathrm{~F}=16,073.40, \mathrm{SEE}=0.390, \mathrm{p}<0.001$
The derived equations converted into conventional units were as follows (units: $\mathrm{Ca}^{2+}$ in $\mathrm{mg} / \mathrm{dl}$, CaTot in $\mathrm{mg} / \mathrm{l}$, Alb in $\mathrm{g} / \mathrm{dl})$ :

$$
\begin{aligned}
& \text { Equation 1: } \mathrm{Ca}^{2+}=1.629 \times \mathrm{CaTot}^{0.5} \\
& \text { Equation 2: } \mathrm{Ca}^{2+}=1.651 \times \mathrm{CaTot}^{0.5}-0.093 \times \mathrm{RF} \\
& \text { Equation 3: } \mathrm{Ca}^{2+}=1.631 \times \mathrm{CaTot}^{0.5}-0.144 \times \mathrm{Alb}^{0.75}+0.317
\end{aligned}
$$

Table 3 presents the concordance and accuracy of the actual values of $\mathrm{Ca}^{2+}$ in cohort $\mathrm{V}$ with the predicted values for the new equations and for the published general equa- 
Table 3. Reliability and accuracy for the predictive equations

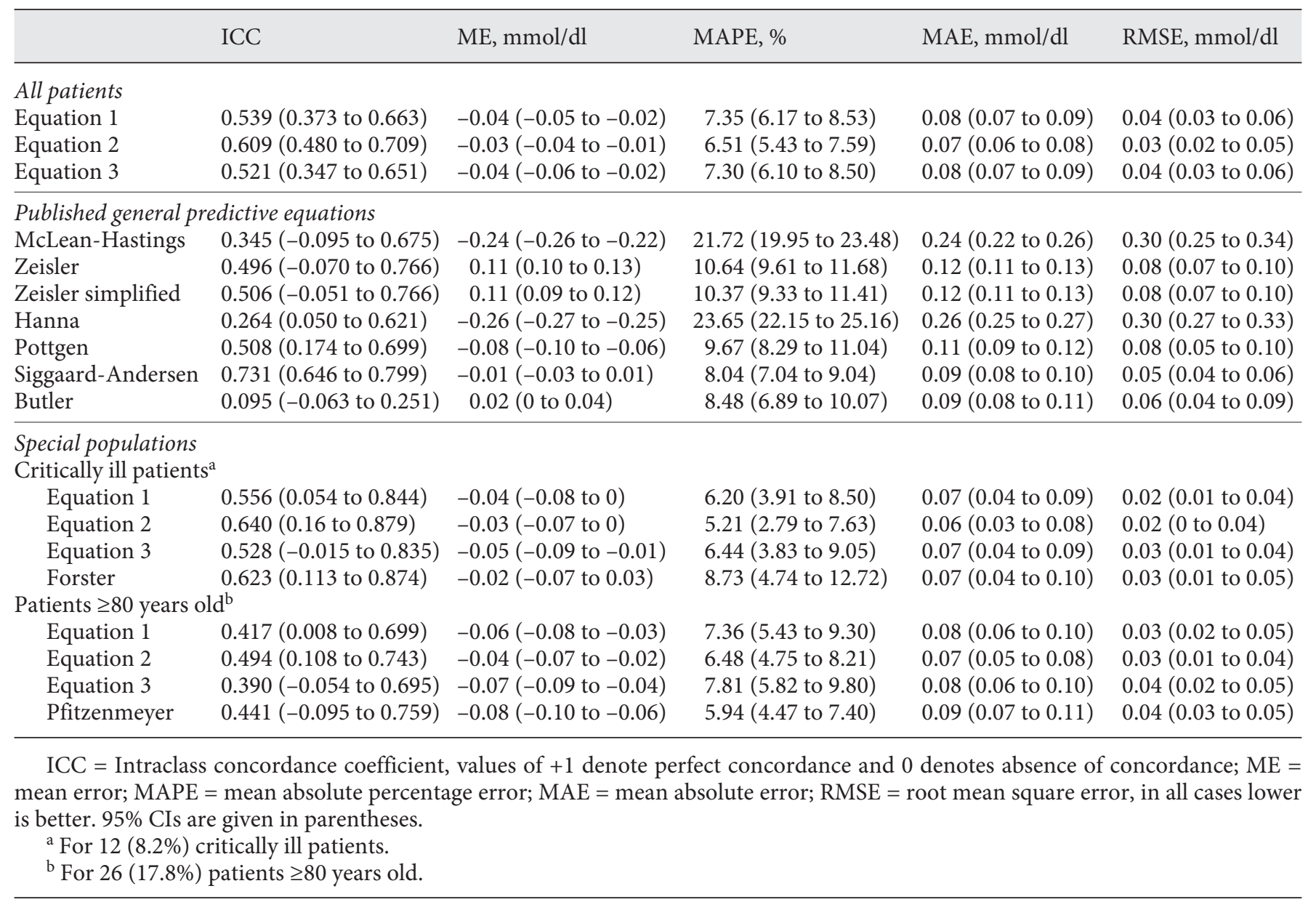

tions. At the bottom of this table, values are shown for specific populations, critically ill or very old ( $\geq 80$ years) patients.

Figure 1 shows the Bland-Altman plots for equations 1, 2 and 3. The agreement on classification by calcemia status and the sensitivity, specificity and likelihood ratio for detection of hypocalcemia are presented in table 4 . Values for hypercalcemia were not calculated since only 7 (4.8\%) patients presented it in cohort V.

As equation 2 contained RF as a parameter, its concordance and accuracy were calculated for patients with renal dysfunction (GFRe $<60 \mathrm{ml} / \mathrm{min} / 1.73 \mathrm{~m}^{2}$ ): mean error $-0.04 \mathrm{mmol} / \mathrm{dl}$ ( $95 \% \mathrm{CI}-0.05$ to 0.02$)$; mean absolute percentage error $6.41 \%$ (95\% CI 5.00-7.82); mean absolute error $0.07 \mathrm{mmol} / \mathrm{dl}$ (95\% CI $0.05-0.08)$; root mean square error $0.03 \mathrm{mmol} / \mathrm{dl}$ (95\% CI 0.02-0.04). Evaluations for predicting hypocalcemia were sensitivity 0.736 , specificity 0.811 , positive likelihood ratio
3.895, negative likelihood ratio 0.325 , agreement kappa 0.496 (95\% CI 0.245-0.807), $\mathrm{p}<0.001$.

\section{Discussion}

The new equations derived and validated in this study predicted better $\mathrm{Ca}^{2+}$, especially equation 2 , than the equations published so far. They contained the usual clinical and laboratory parameters and could be easily calculated, especially equation 1 . In addition, they predicted equally well as the published specific equations for critically ill or very old patients. The purpose of this study was not to obviate the determination of $\mathrm{Ca}^{2+}$ when necessary, but to obtain a reliable approximation when this parameter is not available. $\mathrm{Ca}^{2+}$ determination is not a routine test in several health settings [17,20], has increased costs concerning CaTot $[8,21]$ and has technical difficulties in 

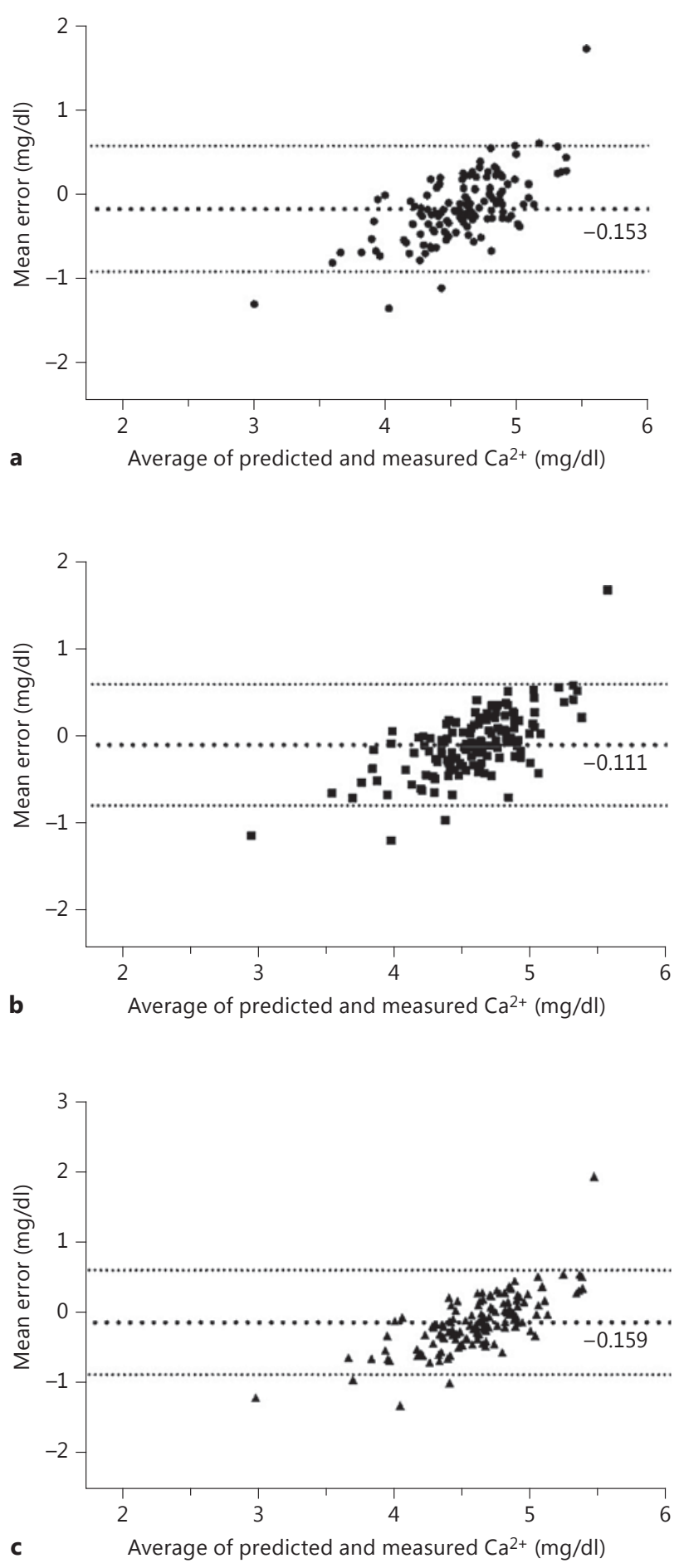

Fig. 1. Bland-Altman plots for equations 1 (a), 2 (b) and 3 (c). processing samples $[20,22] . \mathrm{Ca}^{2+}$ prediction is difficult. Blood calcium homeostasis depends on several factors such as blood proteins, $\mathrm{pH}$, parathyroid hormone levels, calcitonin, 1,25-dihydroxyvitamin D status, intestinal calcium transport proteins, and the action of several organs and systems [2]. In addition, calcium complexes with several blood ligands such as albumin, globulin, bicarbonate, phosphate, lactate and citrate, and it is affected by the anion gap $[23,24]$. The variability of these fractions makes the accuracy of $\mathrm{Ca}^{2+}$ equations lower than equations predicting other biological parameters. Very accurate equations for $\mathrm{Ca}^{2+}$ should include many parameters, but this would be unpractical in a clinical setting.

In these new equations, the square root of $\mathrm{CaT}$ tot was the main independent variable. This mathematical treatment differed from published equations that used the more intuitive CaTot plain value. The transformed albumin in equation 3 is more difficult to calculate. However, the exponent $3 / 4$ or 0.75 . is one of the most frequent exponents found in allometric equations to predict numerous biological phenomena [25]. Albumin [13, 15, 16, 18, 19] and ProtTot $[10-14,17]$ are found in several $\mathrm{Ca}^{2+}$-predicting equations. However, in this study, many equations containing them were discarded due to problems of multicollinearity and independence. In equation 2, RF classification was made using the CKD-EPI equation [9]. Other equations for estimating RF such as MDRD (modification of diet in renal disease) have not been tested, but they were not expected to change the accuracy in predicting. In another study, MDRD was highly correlated with the CKD-EPI equation [26].

The new equations tended to moderately overestimate $\mathrm{Ca}^{2+}$ as shown by the mean error in table 3 . However, they were slightly more accurate than the Siggaard-Andersen equation [14], the most accurate amongst those published. This equation requires the initial calculation of the McLean-Hastings equation [10] and a further multiplication by a coefficient that represents a correction for complex-bound calcium. The need of an initial cumbersome calculation makes the Siggaard-Andersen equation less practical in a clinical setting.

The kappa coefficient is a statistic that takes into account the fact that predictors (equations in this case) will sometimes agree or disagree by chance in classifying the result of a test. It is more accurate than simple percent agreement calculation. In general, the agreement of published predictive equations is from slight to fair in detecting hypocalcemia (table 4). Equation 2 performed better than all of them and presented a moderate agreement. Considering specificity and sensitivity (table 4), again equation 2 performed better than the published predic- 
Table 4. Sensitivity, specificity and likelihood ratio for detecting hypocalcemia and agreement of equations to classify calcemia status

\begin{tabular}{|c|c|c|c|c|c|c|}
\hline Equation & Sensitivity & Specificity & $\begin{array}{l}\text { Positive } \\
\text { likelihood } \\
\text { ratio }\end{array}$ & $\begin{array}{l}\text { Negative } \\
\text { likelihood } \\
\text { ratio }\end{array}$ & Agreement $^{\mathrm{a}}$ & $\mathrm{p}$ value \\
\hline Equation 2 & 0.697 & 0.780 & 3.168 & 0.389 & $0.424(0.296-0.551)$ & $<0.001$ \\
\hline Equation 3 & 0.552 & 0.831 & 3.266 & 0.539 & $0.310(0.184-0.435)$ & $<0.001$ \\
\hline Zeisler & 0.977 & 0.136 & 1.131 & 0.169 & $0.142(0.030-0.254)$ & 0.192 \\
\hline Zeisler simplified & 0.977 & 0.153 & 1.153 & 0.150 & $0.176(0.06-0.291)$ & 0.046 \\
\hline Pottgen & 0.423 & 0.831 & 2.503 & 0.694 & $0.290(0.164-0.416)$ & $<0.001$ \\
\hline Siggaard-Andersen & 0.683 & 0.661 & 2.014 & 0.480 & $0.387(0.245-0.528)$ & $<0.001$ \\
\hline Hanna & 0.089 & 1.000 & - & 0.911 & not calculable ${ }^{b}$ & - \\
\hline Butler & 1.000 & 0.051 & 1.054 & 0.000 & $0.071(0.004-0.138)$ & 0.035 \\
\hline \multicolumn{7}{|c|}{ General predictive equations for corrected calcium } \\
\hline
\end{tabular}

Figures in parentheses are $95 \%$ CI. The sensitivity value of 1 would denote perfect ability to detect hypocalcemia when hypocalcemia was present; the specificity value of 1 would denote perfect ability to exclude hypocalcemia when hypocalcemia was not present; a positive likelihood ratio value of $<1$ increases the probability that the equation confirmed hypocalcemia. Greater values increased the probability; a negative likelihood ratio value of $<1$ increases the probability that the equation discards hypocalcemia. Smaller values increased the probability.

a Weighted kappa, a value of 1 denotes perfect agreement.

b Weighted kappa smaller than mean chance concordance.

tive equations. The values of specificity and sensitivity found in this study were higher than those reported by Dickerson et al. [7], but patients in that study were critically ill trauma patients receiving specialized nutritional support. Performance in hypercalcemia could not be tested since few $(<5 \%)$ patients presented it in cohort V. Hypercalcemia is less frequent than hypocalcemia [17]. Prevalence of hypercalcemia has been reported in $0.7-$ $8.8 \%$ depending on numerous factors $[5,7,15,27]$. Thus, a learning cohort of around 1,000 patients with an additional validation cohort would be needed to derive an accurate predictive equation for hypercalcemia. Published equations have not an acceptable predictive power for hypercalcemia, and better equations are lacking [7].

This study had several limitations. It was retrospective, and the sample size is limited. Patients of special populations, with special conditions that alter calcium homeostasis or with hypercalcemia, have not been represented extensively. Obesity, which in some studies alters calcium homeostasis, was not evaluated as a possible variable. Also, they have not been tested in populations with alterations in calcium homeostasis, such as patients recently thyroidectomized or under renal replacement therapy.
Recently, $\mathrm{Ca}^{2+}$ adjusted for $\mathrm{pH}$ has been questioned as a good marker of calcium status [22]. However, this remains controversial due to possible technical artifacts $[20,22]$ and the actual correlation with $\mathrm{pH}[28,29] . \mathrm{Ca}^{2+}$ adjusted for $\mathrm{pH}$ is still recommended [30].

\section{Conclusion}

Three new equations requiring easily available clinical or laboratory parameters predicted $\mathrm{Ca}^{2+}$ better than the currently available equations. They could be valuable in predicting hypocalcemia but are of limited use in hypercalcemia. They could be useful as an initial approximate value for deciding further calcium tests or as an alternative when the adequate technology to determine $\mathrm{Ca}^{2+}$ is not available.

\section{Disclosure Statement}

There is no conflict of interest. 


\section{References}

$>1$ Gidenne S, Vigezzi JF, Delacour H, et al: Direct determination or estimated value of plasma ionized calcium: indications and limits. Ann Biol Clin (Paris) 2003;61:393-399.

$>2$ Baird GS: Ionized calcium. Clin Chim Acta 2011;412:696-701.

3 McLean FC, Hastings AB: A biological method for the estimations of calcium ion concentrations. J Biol Chem 1934;107:337-350.

4 Larsson L, Magnusson P: Ionized calcium or corrected total calcium? J Bone Miner Res 2003;18:1554-1555; author reply 1556.

$\checkmark 5$ Byrnes MC, Huynh K, Helmer SD, et al: A comparison of corrected serum calcium levels to ionized calcium levels among critically ill surgical patients. Am J Surg 2005;189:310314.

-6 Gouri A, Dekaken A: A comparison of corrected serum calcium levels to ionized calcium levels in haemodialysis patients. Ann Biol Clin (Paris) 2012;70:210-212.

-7 Dickerson RN, Alexander KH, Minard G, et al: Accuracy of methods to estimate ionized and 'corrected' serum calcium concentrations in critically ill multiple trauma patients receiving specialized nutrition support. JPEN J Parenter Enteral Nutr 2004;28:133-141.

$>8$ Baird GS, Rainey PM, Wener M, et al: Reducing routine ionized calcium measurement. Clin Chem 2009;55:533-540.

$>9$ Levey AS, Stevens LA, Schmid CH, et al: A new equation to estimate glomerular filtration rate. Ann Intern Med 2009;150:604-612.

10 McLean FC, Hastings AB: The state of calcium in the fluids of the body. I. The conditions affecting the ionization of calcium. J Biol Chem 1935;108:285-321.

11 Zeisler EB: Determination of diffusible serum calcium. Am J Clin Pathol 1954;24:588-593.

12 Hanna EA, Nicholas HO, Chamberlin JA: Nomogram for estimating diffusible serum calcium. Clin Chem 1964;10:235-240.
13 Pottgen P, Davis ER: Why measure total serum Ca? Clin Chem 1976;22:1752-1753.

14 Siggaard-Andersen O, Thode J, Fogh-Andersen N: Nomograms for calculating the concentration of ionized calcium of human blood plasma from total calcium, total protein and/ or albumin, and $\mathrm{pH}$. Scand J Clin Lab Invest 1983;43:57-64.

15 Forster J, Querusio L, Burchard KW, et al: Hypercalcemia in critically ill surgical patients. Ann Surg 1985;202:512-518.

16 Pfitzenmeyer P, Martin I, d'Athis P, et al: A new formula for correction of total calcium level into ionized serum calcium values in very elderly hospitalized patients. Arch Gerontol Geriatr 2007;45:151-157.

17 Payne RB, Little AJ, Williams RB, et al: Interpretation of serum calcium in patients with abnormal serum proteins. Br Med J 1973; iv:643-646.

18 James MT, Zhang J, Lyon AW, et al: Derivation and internal validation of an equation for albumin-adjusted calcium. BMC Clin Pathol 2008;8:12.

19 Butler SJ, Payne RB, Gunn IR, et al: Correlation between serum ionised calcium and serum albumin concentrations in two hospital populations. Br Med J (Clin Res Ed) 1984;289: 948-950.

20 Glendenning P: It is time to start ordering ionized calcium more frequently: preanalytical factors can be controlled and postanalytical data justify measurement. Ann Clin Biochem 2013;50:191-193.

21 Di Capua P, Pfeffer M: Quantifying the impact of unnecessary ionized calcium measurements. J Gen Intern Med 2013;28(suppl 1): S163.
22 Lam V, Dhaliwal SS, Mamo JC: Adjustment of ionized calcium concentration for serum $\mathrm{pH}$ is not a valid marker of calcium homeostasis: implications for identifying individuals at risk of calcium metabolic disorders. Ann Clin Biochem 2013;50:224-229.

23 Nordin BE, Need AG, Hartley TF, et al: Improved method for calculating calcium fractions in plasma: reference values and effect of menopause. Clin Chem 1989;35:14-17.

24 Takano S, Kaji H, Hayashi F, et al: A calculation model for serum ionized calcium based on an equilibrium equation for complexation. Anal Chem Insights 2012;7:23-30.

25 West GB, Brown JH: The origin of allometric scaling laws in biology from genomes to ecosystems: towards a quantitative unifying theory of biological structure and organization. J Exp Biol 2005;208:1575-1592.

26 Ovbiagele B: Relation of new and old formulas for estimating creatinine clearance among stroke survivors. Med Princ Pract 2010;19: 319-320.

27 Lindner G, Felber R, Schwarz C, et al: Hypercalcemia in the ED: prevalence, etiology, and outcome. Am J Emerg Med 2013;31:657-660.

28 Çakar M, Bulucu F, Kurt Ö, et al: Arterial blood $\mathrm{pH}$ seems to be less important in determining the serum ionized calcium levels. Nephrol Dial Transplant 2013;28(suppl 1): i79-i80.

29 Thode J, Holmegaard SN, Transbol I, et al: Adjusted ionized calcium (at pH 7.4) and actual ionized calcium (at actual pH) in capillary blood compared for clinical evaluation of patients with disorders of calcium metabolism. Clin Chem 1990;36:541-544.

-30 Burnett RW, Christiansen TF, Covington AK, et al: IFCC recommended reference method for the determination of the substance concentration of ionized calcium in undiluted serum, plasma or whole blood. Clin Chem Lab Med 2000;38:1301-1314. 